\title{
MDS/AML del(11)(q14) Share Common Morphological Features Despite Different Chromosomal Breakpoints
}

\author{
IRENE DAMBRUOSO ${ }^{1}$, ROSANGELA INVERNIZZI $^{2}$, MARINA BONI $^{1}$, RITA ZAPPATORE $^{1}$, ILARIA GIARDINI ${ }^{1}$, \\ MARIA PAOLA CAVIGLIANO ${ }^{1}$, BARBARA ROCCA ${ }^{1}$, CELESTE CALVELLO $^{1}$, RAFFAELLA BASTIA ${ }^{2}$, \\ MARILENA CARESANA ${ }^{1}$, FRANCESCA PASI ${ }^{3,4}$, ROSANNA NANO $^{4}$ and PAOLO BERNASCONI ${ }^{1}$ \\ Divisions of ${ }^{1}$ Hematology, ${ }^{2}$ Internal Medicine, and ${ }^{3}$ Radiotherapy, \\ Fondazione IRCCS Policlinico San Matteo, Pavia, Italy; \\ ${ }^{4}$ Laboratory of Neuro Radio Experimental Biology, \\ Department of Biology and Biotechnology "L. Spallanzani", University of Pavia, Pavia, Italy
}

\begin{abstract}
In myelodysplatic syndromes and acute myeloid leukemia $(M D S / A M L)$ deletion of the 11 q14 region is a rare chromosomal defect (incidence: 0.6-1.0\%), included within the intermediate risk criteria by the International Prognostic Scoring System. No fluorescence in situ hybridization (FISH) study has yet been performed to identify a common breakpoint region $(C B R)$. In our study through FISH with bacterial artificial chromosomes and commercial probes, we analyzed seven patients with MDS/AML harboring 11 q14 deletion on conventional cytogenetic analysis. FISH revealed deletions in five patients and amplifications in two. Three patients with deletion carried a CBR, two had a deletion involving a more centromeric breakpoint. These five patients exhibited multilineage dysplasia, blast cells with large round nuclei, loose chromatin, small and abundant nucleoli, and vacuolated cytoplasm with very thin Auer bodies. In conclusion, the morphological features which occur independently of the extent of the deletion are of multilineage dysplasia in MDS and leukemic blasts strongly reactive to peroxidase in AML; despite the variable size of the deleted area, some patients harbor a CBR.
\end{abstract}

Long-arm deletions of chromosome 11 as a sole abnormality or a part of a non-complex karyotype are frequent chromosomal lesions found in acute myeloid leukemia (AML), but are uncommon in myelodysplatic syndromes (MDS) (1). From a prognostic point of view, the International Prognostic Scoring System (IPSS) includes single del(11q)

Correspondence to: Irene Dambruoso, Division of Hematology, Fondazione IRCCS Policlinico San Matteo, 27100-Pavia, Italy. Tel: +39 0382503065, Fax: +39 0382502250, e-mail: i.dambruoso@smatteo.pv.it

Key Words: MDS/AML, chromosome 11, deletion, morphology, FISH, del(11)(q13-14). within the intermediate-risk cytogenetic category (2), whereas recent data (3-5), including our own (6), suggest that this is associated with a better clinical outcome. Thus, based on these data the New Comprehensive Cytogenetic Scoring System includes it within the very good category of risk (7).

In AML, most 11q defects are in band 11q23 which contains the lysine methyltransferase 2A (KMT2A) gene, sometimes involved in cryptic translocations, as revealed by fluorescence in situ hybridization (FISH) and real-time polymerase chain reaction studies (RT-PCR). In MDS, KMT2A rearrangements are extremely rare, the extent of $11 \mathrm{q}$ deletion is quite variable (8), and amplifications of band 11q23-24 involving other potentially oncogenic genes rather than $K M T 2 A$ gene may be revealed (9). In addition, in MDS and AML, 11q lesions are frequently present along with other abnormalities and are rarely seen as a single defect. Deletions involving the more proximal band 11q14 are even rarer, especially as a single defect (10).

Based on these data, we decided to look for a possible common breakpoint region (CBR) in seven patients with MDS/AML who carried the 11q14 deletion on conventional cytogenetic (CC) studies and to correlate this chromosomal lesion with morphological and clinicohematological data.

\section{Materials and Methods}

Patients. A total of seven patients with del(11)(q14) were identified from among the 852 patients recruited at the Division of Hematology, Fondazione IRCCS Policlinico San Matteo, Pavia, Italy, between January 1995 and December 2011. All patients were classified according to the WHO classification (1). Diagnostic procedures performed at clinical diagnosis were carried out as already reported (4).

Cytogenetic studies. Conventional cytogenetic (CC) studies were performed on bone marrow cells (4). Chromosomal identification and karyotype description were made according to the International 
System for Chromosome Nomenclature (11). In the presence of three or more chromosomal abnormalities the karyotype was defined as complex.

FISH analysis. In order to establish the extent of chromosome 11q defect, 21 bacterial artificial chromosomes (BAC) probes spread over band 11q13.4-q22.3 were chosen. The BAC clones (Table I) were selected from the RPCI-11 human library according to the University of California Santa Cruz Human Genome Assembly (https://genome.ucsc.edu) and were obtained from BAC/PAC Resources of the Children's Hospital and Research Center at Oakland (CA, USA). BAC probes were prepared and applied as previously described (12). Briefly, recombinant bacteria were cultured in LB Broth Medium with Chloramphenicol (Sigma Aldrich, St. Louis, MO, USA). BAC DNA extraction was performed with PhasePrep BAC DNA kit (Sigma Aldrich, St. Louis, MO, USA). Subsequently, probes were labelled with the dig-dUTP nick translation kit (Roche Diagnostics, Rotkreuz Switzerland) and suspended in $50 \%$ formamide, $1 \%$ Tween-20, $20 \%$ dextran sulfate along with salmon sperm DNA and Competitor DNA (Cot-1 DNA) (Roche Diagnostics).

For FISH investigations, BAC probes and target DNA were codenaturated at $75^{\circ} \mathrm{C}$ for 5 minutes. Hybridization was carried out in a humidified chamber at $37^{\circ} \mathrm{C}$ under coverslips. Posthybridization washes were performed in $0.4 \times$ saline-sodium citrate (SSC) with $0.3 \%$ Nonidet $\mathrm{P} 40$ at $72^{\circ} \mathrm{C}$ for 2 minutes and then in $2 \mathrm{x} \mathrm{SSC}$ at room temperature for 2 minutes. The probes were labelled and revealed by anti-digoxigenin-rhodamine FAB fragments (Sigma Aldrich). Slides were counterstained with (4',6diamidin-2-fenilindolo). Metaphases were analyzed with an Olympus BX61 epifluorescence microscope (Olympus srl, Milan, Italy) and images captured by a Cytovision System (Olympus srl). Whole Chromosome Painting 11 - WCP11 (from Kreatech Diagnostics, Amsterdam, the Netherlands), locus specific identifier cyclin D1/immunoglobulin heavy chain (LSI $C C N D 1 / C E P 11)$, LSI $M L L$ and LSI ataxia-telangiectasia mutated (ATM) (from Vysis, Abbot Laboratories, Abbott Park, IL, USA) were applied according to the manufacturers' guidelines and used as internal controls.

\section{Results}

Patients. The clinical features of our patients are listed in Table II. Their median age was 62 (range=25-74) years. According to WHO classification, two patients (patients 1 and 6) were diagnosed as having refractory cytopenia with multilineage dysplasia (RCMD), one as having refractory anemia with ring sideroblasts (RARS) (patient 4), three with AML (patients 2, 3 and 7) and one with therapy-related AML (patient 5). According to the revised IPSS score the patient with RARS was considered at intermediate risk; one patient with RCMD (patient 1) was considered at very-low risk, and the other (patient 6) at poor risk exclusively based on karyotype. Patient 6 harbored three cytogenetic defects with only moderate anemia $(\mathrm{Hb}=9.4 \mathrm{~g} / \mathrm{dl})$ and $3 \%$ bone marrow blasts. During the follow-up period, the patients with RARS progressed to AML and patient 6 progressed to refractory anemia with excess blasts type-2 (RAEB-2). None of the
Table I. List of bacterial artificial chromosomes probes employed in the study.

\begin{tabular}{lccc}
\hline Probe & Position & Probe & Position \\
\hline RP11-93M11 & $11 \mathrm{q} 13.4$ & RP11-19P3 & $11 \mathrm{q} 14.1$ \\
RP11-30J7 & $11 \mathrm{q} 13.5$ & RP11-23O14 & $11 \mathrm{q} 14.2$ \\
RP11-259H21 & $11 \mathrm{q} 13.5$ & RP11-35N2 & $11 \mathrm{q} 14.3$ \\
RP11-57M20 & $11 \mathrm{q} 13.5$ & RP11-61E17 & $11 \mathrm{q} 21$ \\
RP11-35D24 & $11 \mathrm{q} 13.5-14.1$ & RP11-44M8 & $11 \mathrm{q} 21-\mathrm{q} 22.1$ \\
RP11-150F7 & $11 \mathrm{q} 13.5-14.1$ & RP11-99C10 & $11 \mathrm{q} 22$ \\
RP11-62B13 & $11 \mathrm{q} 14.1$ & RP11-265O1 & $11 \mathrm{q} 22.1$ \\
RP11-451K5 & $11 \mathrm{q} 14.1$ & RP11-4C24 & $11 \mathrm{q} 22.2$ \\
RP11-378O2 & $11 \mathrm{q} 14.1$ & RP11-179B7 & $11 \mathrm{q} 22.3$ \\
RP11-300P22 & $11 \mathrm{q} 14.1$ & RP11-5N5 & $11 \mathrm{q} 22.3$ \\
RP11-88D4 & $11 \mathrm{q} 14.1$ & & \\
\hline
\end{tabular}

four patients with AML showed FMS-like tyrosine kinase-3 (FLT3) internal tandem duplication or nucleophosmin 1 (NPM1) mutation on RT-PCR. CCAAT/enhancer-binding protein alpha (CEBPA) mutations were not sought.

The elderly patients with MDS received supportive treatments only, whereas the two elderly patients with AML (patients 5 and 7) received transfusions and hydroxyurea in order to control the high leukocyte number. The other two patients with AML (one male and one female) received standard induction chemotherapy (daunorubicin and cytarabine). Both patients achieved a complete remission that lasted 5 and 11 months respectively. At relapse, the male patient was submitted to various schedules of re-induction chemotherapy that were unsuccessful and he died of fungal infection. The female patient did not respond to a new induction course and died of infections 2 months later. The median follow-up was 28 (range=9-119) months.

From a morphological point of view, the three patients with del(11)(q14) AML showed peripheral blood and bone marrow blasts with similar morphological features: rather large size with round nuclei, loose chromatin, small nucleoli, and abundant, agranular, often vacuolated cytoplasm. Needle-like Auer bodies were observed in rare cells. Most blasts had cytoplasmic vacuoles and Auer bodies were strongly reactive to peroxidase. These same peculiar morphological features were also presented by the leukemic blasts of the patients with RARS at the time of AML evolution.

CC studies. Monosomy 11 was revealed in one patient, a $11 q 13$ deletion in another, a 11q14 deletion in four and a translocation involving band 11q13 in one patient (Table III). The chromosome 11 alteration was present as a single defect in one patient, plus another defect in three, plus two other defects in three. 
Table II. Clinical and morphological features of patients with myelodysplastic syndrome (MDS)/acute myeloid leukemia (AML).

\begin{tabular}{|c|c|c|c|c|c|c|c|}
\hline Patient & $\begin{array}{l}\text { Age, years/ } \\
\text { gender }\end{array}$ & $\begin{array}{c}\text { Date of } \\
\text { diagnosis }\end{array}$ & Diagnosis & $\begin{array}{c}\text { BM blasts } \\
(\%)\end{array}$ & Dysplasia & Comments & $\begin{array}{c}\text { FU, months/ } \\
\text { status }\end{array}$ \\
\hline 1. & $60 / \mathrm{F}$ & January 2001 & RCMD & $<2$ & $\mathrm{E}, \mathrm{G}, \mathrm{M}$ & & $119^{\dagger}$ \\
\hline 2. & $25 / \mathrm{M}$ & December 1995 & AML-M2 & 90 & $\mathrm{E}, \mathrm{G}$ & Auer rods, vacuolated blasts (11\%) & $9 \dagger$ \\
\hline 3. & $30 / \mathrm{F}$ & January 1997 & AML M2 & 80 & E, G & Auer rods, vacuolated blasts ( $20 \%)$ & $13^{\dagger}$ \\
\hline \multirow[t]{3}{*}{4.} & $62 / \mathrm{M}$ & September 2004 & RARS & 1 & $\mathrm{E}$ & Auer rods, vacuolated blasts ( $42 \%$ ) & $61^{\dagger}$ \\
\hline & & December 2005 & RCMD-RS & 3 & $\mathrm{E}, \mathrm{M}$ & & \\
\hline & & June 2007 & $\begin{array}{l}\text { AML with MDS- } \\
\text { related changes }\end{array}$ & 63 & $\mathrm{E}, \mathrm{M}$ & & \\
\hline 5. & $66 / \mathrm{M}$ & July 2004 & T-AML & 45 & $\mathrm{E}, \mathrm{G}$ & Auer rods, vacuolated blasts $(31 \%)$ & $26^{\dagger}$ \\
\hline \multirow[t]{3}{*}{6.} & $74 / \mathrm{M}$ & January 2003 & RCMD & 3 & $\mathrm{E}, \mathrm{M}$ & & $56^{*}$ \\
\hline & & July 2004 & RAEB-1 & 6 & $\mathrm{E}, \mathrm{M}$ & & \\
\hline & & April 2007 & RAEB-2 & 10 & E, M & & \\
\hline 7. & $72 / \mathrm{M}$ & November 2000 & AML M4 & 82 & E, G & & $10^{\dagger}$ \\
\hline
\end{tabular}

F: Female, M: male, BM: bone marrow, RCMD: refractory cytopenia with multilineage dysplasia, RARS: refractory anemia with ring sideroblasts, RCMD-RS: RCMD with ringed sideroblasts, T-AML : therapy-related AML, RAEB-1: refractory anemia with excess of blasts type 1, RAEB-2: refractory anemia with excess of blasts type 2, E: erythroid, G: granulocytic, M: megakaryocytic, FU: follow-up, †dead, *alive at the last follow-up.

Table III. Diagnostic, cytogenetic and fluorescence in situ hybridization (FISH) results for the seven studied patients.

\begin{tabular}{|c|c|c|c|c|c|c|}
\hline \multirow[b]{2}{*}{ Patient } & \multirow[b]{2}{*}{ Karyotype } & \multicolumn{5}{|c|}{ FISH } \\
\hline & & Result & Breakpoints & Probe position & Base position & $\mathrm{Mb}$ \\
\hline \multirow[t]{2}{*}{1} & $46, \mathrm{XX},-11,+\mathrm{mar}$ & Deletion & Between probe $19 \mathrm{P} 13$ and $23 \mathrm{O} 14$ & $11 \mathrm{q} 14.1$ & $84,669,674$ & 2.3 \\
\hline & & & & $11 \mathrm{q} 14.2$ & $86,995,758$ & \\
\hline \multirow[t]{2}{*}{2} & 46,XY,del(11)(q14),del(13) & Deletion & Between probe $19 \mathrm{P} 13$ and $23 \mathrm{O} 14$ & $11 \mathrm{q} 14.1$ & $84,669,674$ & 2.3 \\
\hline & $(\mathrm{q} 11 \mathrm{q} 14), \operatorname{del}(9)(\mathrm{p} 21)$ & & & $11 \mathrm{q} 14.2$ & $86,995,758$ & \\
\hline \multirow[t]{2}{*}{3} & $46, \mathrm{XX}, \operatorname{del}(11)(\mathrm{q} 14), \operatorname{del}(12)(\mathrm{p} 12)$ & Deletion & Between probe $19 \mathrm{P} 13$ and $23 \mathrm{O} 14$ & $11 \mathrm{q} 14.1$ & $84,669,674$ & 2.3 \\
\hline & & & & $11 \mathrm{q} 14.2$ & $86,995,758$ & \\
\hline \multirow[t]{2}{*}{4} & 46,XY,del(11)(q14),del(17)(p11) & Deletion & Between probe 19P13 and 88D4 & $11 \mathrm{q} 14.1$ & $84,669,674$ & 4.5 \\
\hline & & & & & $80,147,023$ & \\
\hline \multirow[t]{2}{*}{5} & 46,XY,del(11)(q14) & Deletion & Between probe $378 \mathrm{O} 2$ and $451 \mathrm{~K} 5$ & $11 \mathrm{q} 14.1$ & $84,669,674$ & 5.9 \\
\hline & & & & & $78,699,532$ & \\
\hline \multirow[t]{2}{*}{6} & 46,XY,t(1;?)(q32;?),del(11) & Amplification & From probe $19 \mathrm{P} 13$ to $23 \mathrm{O} 14$ & $11 q 14.1$ & $84,669,674$ & 2.3 \\
\hline & $(\mathrm{q} 13), \mathrm{t}(17 ; ?)(\mathrm{q} 24 ; ?)$ & & & $11 \mathrm{q} 14.2$ & $86,995,758$ & \\
\hline \multirow[t]{2}{*}{7} & $47, X Y,+8, \operatorname{inv}(16)(\mathrm{p} 13 \mathrm{q} 22)$ & Amplification & From probe $23 \mathrm{O} 14$ to $93 \mathrm{M} 11$ & $11 \mathrm{q} 13.4$ & $72,700,570$ & 14.3 \\
\hline & $\operatorname{der}(17) t(11 ; 17)(q 13 ; p 13)$ & & & $11 \mathrm{q} 14.2$ & $86,995,758$ & \\
\hline
\end{tabular}

FISH results. In patient 1 , FISH excluded monosomy 11 and revealed that the chromosome defined as a marker by $\mathrm{CC}$ was instead a number 11 with a terminal deletion in which the breakpoint was localized at band 11q14. In particular, the BAC probe RP11-19P3 (11q14.1) was maintained, whereas the RP11-23O14 probe (11q14.2) was lost. Patients 2 and 3 shared this same breakpoint (Table III). In contrast, patients 4 and 5 , who showed a potential breakpoint within this same chromosomal band by $\mathrm{CC}$, presented a breakpoint within a more centromeric region on FISH studies. In particular, in patient 4, the RP11-88D4 BAC probe was maintained and the RP11-19P3 probe was lost, whereas in patient 5, the
RP11-451K5 BAC probe was maintained and the RP1137802 probe was lost. Thus, even if all five of these patients carried the same 11q14 deletion on CC analyses, three shared a CBR and two harbored different breakpoints (Figure 1).

In patients 6 and 7, FISH revealed an amplification instead of a deletion: the smallest amplified area was between the BAC probes RP11-19P3 and RP11-23014.

In both patients, a WCP11 probe revealed that the amplified area was no longer localized on chromosome 11 but had been translocated to another chromosome. In these patients, the LSI MLL and LSI ATM probes presented a normal pattern and excluded any cryptic rearrangements. 
In order to exclude amplification of the cyclin D1 locus, all patients were tested with the LSI CCND1/CEP11 probe, which revealed a normal pattern in all.

\section{Discussion}

The present study aimed at establishing whether peculiar clinicohematological and morphological findings present in patients with a $\operatorname{del}(11)(\mathrm{q} 14)$ as determined by CC could be due to a CBR. In our series of 852 patients with MDS/AML, $\operatorname{del}(11)(q 14)$ was revealed in seven patients $(0.8 \%)$, a prevalence in accordance with the literature (13). In fact, a recent study reported that del(11q) as a single defect or a part of a non-complex karyotype occurs at an incidence of approximately $0.6 \%$ (13). However, most patients exhibited an interstitial long-arm deletion defined as $\operatorname{del}(11)(q 13 q 23)$ or del(11)(q13q33), and only three had a terminal deletion involving bands q13-q14. Considering the literature data, this same deletion has been identified in three additional patients $(10,14)$. Thus, to date, $\operatorname{del}(11)(q 14)$ has been reported in a total of six patients (one with myeloproliferative neoplasm, two with refractory anemia without or with ringed sideroblasts, two with refractory cytopenia with multilineage dysplasia and one with AML) who were more frequently females (male:female ratio 1:2), with a median age of 62 (range $=57-88$ ) years. In our series, $\mathrm{CC}$ revealed $\operatorname{del}(11)(\mathrm{q} 14)$ in seven patients but FISH confirmed the deletion only in five and showed that the other two patients harbored an amplification of $11 \mathrm{q}$ material which had been translocated to other chromosomes. $\operatorname{Del}(11)(q 14)$ was more common in males than in females (ratio 3:2) and the median age of patients with this feature was 62 (range=25-74) years. All our patients with $\operatorname{del}(11)(q 14)$ MDS/AML except one presented with either bi-lineage or tri-lineage dysplasia. In addition, and more importantly, the unifying morphological feature in all our three of our patients with $\operatorname{del}(11)(q 14)$ AML was that their leukemia cells exhibited rather large, round nuclei with loose chromatin and small nucleoli in an abundant, agranular and often vacuolated cytoplasm containing very few needle-like Auer bodies. Most blasts exhibited cytoplasmic vacuoles and Auer bodies strongly reactive to peroxidase. The fact that the only patients with RARS who progressed to AML developed a leukemia cell population exhibiting these same morphological and cytochemical features demonstrates that they were peculiar to the $\operatorname{del}(11)(\mathrm{q} 14)$ blast cell population. From a prognostic point of view, the two patients, one with RCMD and one with therapy-related AML, who only presented del(11)(q14) as a single defect survived 119 and 28 months respectively. This datum supports previous findings (3-6) and confirms that patients with MDS with this chromosomal defect should be included within the very favorable risk group as recently stated by the revised IPSS score (15).

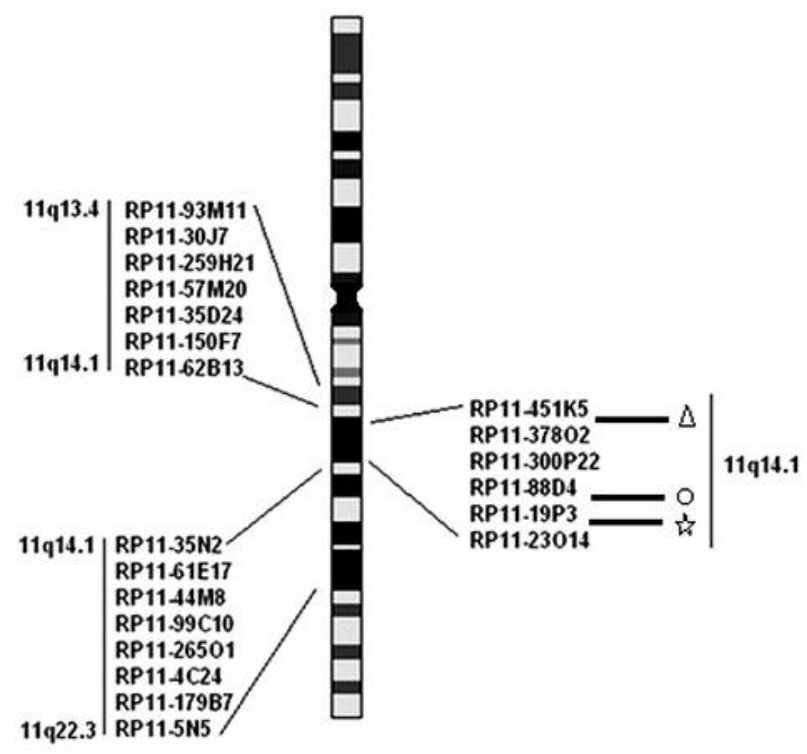

Figure 1. Breakpoint positions identified in chromosome 11 for patients

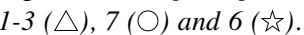

When FISH was employed to define more precisely the extent of the deletion and to identify a potentially CBR, three patients (one with RCMD and two with AML) presented a breakpoint localized in a $2.3 \mathrm{Mb}$-sized region which was mapped between bands 11q14.1-q14.2 (between the RP1119P13 and RP11-23O14 BAC probes). Another two patients (one with RARS and one with therapy-related AML) exhibited more centromeric breakpoints, revealing that breakpoints at band 11q14 may be quite variable. In addition and more importantly, even in the three patients in whom FISH studies allowed a more precise determination of the location of the chromosomal breakpoint, it was impossible to identify gene(s) having a potential role in the pathogenesis of $\operatorname{del}(11)(q 14)$ MDS/AML. This is not a surprising finding as similar cytogenetic and molecular features have been associated with $5 \mathrm{q}$ deletion (16). In particular, the lack of evidence for homozygous inactivation of any genes within the $5 \mathrm{q}$-common deleted region raises the possibility that the disease is caused by haploinsufficiency for one or more genes. The same situation could also occur for del(11q), which seems to be the most frequently associated with loss of heterozigosity (17).

In conclusion, our FISH study reveals that i) del(11)(q14) is a very rare clonal defect in MDS/AML; ii) the unifying morphological features which occur independently of the extent of the deletion are multilineage dysplasia in patients with MDS and leukemic blasts with cytoplasmic vacuoles and Auer bodies strongly reactive to peroxidase in those with AML; iii) despite the quite variable size of the 11q-deleted area, some patients may harbor a CBR. 


\section{Ethical Approval}

All procedures performed in these studies involving human participants were in accordance with the ethical standards of the institutional or national research committee and with the 1964 Helsinki declaration and its later amendments or comparable ethical standards

\section{Conflicts of Interest}

The Authors declare that they have no conflict of interest in regard to this study.

\section{References}

1 Vardiman JW, Thiele J, Arber DA, Brunning RD, Borowitz MJ, Porwit A, Harris NL, Le BeauMM, Hellström-Lindberg E, Tefferi A and Bloomfield CD: The 2008 revision of the World Health Organization (WHO) Classification of Myeloid Neoplasms and Acute Leukaemia: Rationale and important changes. Blood 114: 937-951, 2009.

2 Greenberg P, Cox C, LeBeau MM, Fenaux P, Morel P, Sanz G, Sanz M, Vallespi T, Hamblin T, Oscier D, Ohyashiki K, Toyama $\mathrm{K}$, Aul C, Mufti G and Bennett J: International scoring system for evaluating prognosis in myelodysplastic syndromes. Blood 89: 2079-2088, 1997.

3 Solé F, Luño E, Sanzo C, Espinet B, Sanz GF, Cervera J, Calasanz MJ, Cigudosa JC, Millà F, Ribera JM, Bureo E, Marquez ML, Arranz E and Florensa L: Identification of novel cytogenetic markers with prognostic significance in a series of 968 patients with primary myelodysplastic syndromes. Haematologica 90: 1168-1178, 2005.

4 Bernasconi P, Klersy C, Boni M, Cavigliano PM, Calatroni S, Giardini I, Rocca B, Zappatore R, Caresana M, Quarna J, Lazzarino $\mathrm{M}$ and Bernasconi $\mathrm{C}$ : Incidence and prognostic significance of karyotype abnormalities in de novo primary myelodysplastic syndromes: a study on 331 patients from a single institution. Leukemia 19: 1424-1431, 2005.

5 Haase D, Germing U, Schanz J, Pfeilstöcker M, Nösslinger T, Hildebrandt B, Kundgen A, Lübbert M, Kunzmann R, Giagounidis AA, Aul C, Trümper L, Krieger O, Stauder R, Müller TH, Wimazal F, Valent P, Fonatsch C and Steidl C: New insights into the prognostic impact of the karyotype in MDS and correlation with subtypes: evidence from a core dataset of 2124 patients. Blood 110: 4385-4395, 2007.

6 Bernasconi P, Klersy C, Boni M, Cavigliano PM, Calatroni S, Giardini I, Rocca B, Zappatore R, Caresana M, Dambruoso I, Lazzarino $\mathrm{M}$ and Bernasconi $\mathrm{C}$ : WHO classification in combination with cytogenetic markers improve the prognostic stratification of patients with de novo primary myelodysplastic syndromes (MDS). Br J Haematol 137: 193-205, 2007.

7 Schanz J, Tüchler H, Solé F, Mallo M, Luño E, Cervera J, Granada I, Hildebrandt B, Slovak ML, Ohyashiki K, Steidl C, Fonatsch C, Pfeilstöcker M, Nösslinger T, Valent P, Giagounidis A, Aul C, Lübbert M, Stauder R, Krieger O, Garcia-Manero G, Faderl S, Pierce S, Le Beau MM, Bennett JM, Greenberg P, Germing $U$ and Haase D: New comprehensive cytogenetic scoring system for primary myelodysplastic syndromes (MDS) and oligoblastic acute myeloid leukemia after MDS derived from an international database merge. J Clin Oncol 30: 820-829, 2012.
8 Bain BJ, Moorman AV, Johansson B, Mehta AB and SeckerWalker LM: Myelodysplastic syndromes associated with 11q23 abnormalities. Leukemia 12: 834-839, 1998.

9 Zatkova A, Ullmann R, Rouillard JM, Lamb BJ, Kuick R, Hanash SM, Schnittger S, Schoch C, Fonatsch C and Wimmer K: Dinstinct sequences on 11q13.5 and 11q23-24 are frequently coamplified with $M L L$ in complexly organized 11q amplicons in AML/MDS patients. Genes Chromosome Canc 39: 263-276, 2004.

10 Panani AD, Pappa V, Papageorgiou S, Stamatelli F, Raptis SA: Deletion(11)(q13) as the sole anomaly in myeloid malignancies: four new cases and a short review. Ann Hematol 83: 153-155, 2004.

11 Schaffer LG, McGowan-Jordan J, Schmidt M (eds.): ISCN 2013: An International System for Human Cytogenetic Nomenclature. S. Karger, Basel. 2013.

12 Dambruoso I, Boni M, Rossi M, Zappasodi P, Calvello C, Zappatore R, Cavigliano PM, Giardini I, Rocca B, Caresana M, Astori C, Cazzola M, Castagnola C and Bernasconi P: Detection of TET2 abnormalities by fluorescence in situ hybridization in 41 patients with myelodysplastic syndrome. Cancer Genet 205: 285-94, 2012.

13 Wang SA, Abruzzo LV, Hasserjian RP, Zhang L, Hu Y, Zhang Y, Zhao M, Galili N, Raza A, Medeiros LJ and Garcia-Manero G, Miranda RN: Myelodysplastic syndromes with deletions of chromosome 11q lack cryptic $M L L$ rearrangement and exhibit characteristic clinicopathologic features. Leukemia Res 35: 351357, 2011.

14 Nakanishi M, Tanaka K, Shintani T, Takahashi T and Kamada $\mathrm{N}$ : Chromosomal instability in acute myelocytic leukemia and myelodysplastic syndrome patients among atomic bomb survivors. J Radiat Res 40: 159-167, 1999.

15 Greenberg PL, Tuechler H, Schanz J, Sanz G, Garcia-Manero G, Solé F, Bennett JM, Bowen D, Fenaux P, Dreyfus F, Kantarjian H, Kuendgen A, Levis A, Malcovati L, Cazzola M, Cermak J, Fonatsch C, Le Beau MM, Slovak ML, Krieger O, Luebbert M, Maciejewski J, Magalhaes SM, Miyazaki Y, Pfeilstöcker M, Sekeres M, Sperr WR, Stauder R, Tauro S, Valent P, Vallespi T, van de Loosdrecht AA, Germing $U$ and Haase D: Revised international prognostic scoring system for myelodysplastic syndromes. Blood 120(12): 2454-65, 2012.

16 Ebert BL: Deletion 5q in myelodysplastic syndrome: a paradigm for the study of hemizygous deletions in cancer. Leukemia 23: 1252-1256, 2009.

17 Mori N, Morosetti R, Hoflehner E, Lübbert M, Mizoguchi H and Koeffler HP: Allelic loss in the progression of myelodysplastic syndrome. Cancer Res 60: 3039-3042, 2000.
Received November 23, 2016

Revised December 23, 2016

Accepted January 9, 2017 